\title{
Multi-dimensional Indices of Achievement and Poverty: Comments
}

\section{Nora Lustig}

The 2011 June issue of the Journal of Economic Inequality published four articles in its Forum section on multi-dimensional indices of achievement and poverty. Given the importance of the subject, the Journal decided to invite a small group of leading scholars to write brief comments to help move the discussion forward. In particular, we encouraged these scholars to comment briefly on the following two questions: Is aggregating dimensions of poverty and wellbeing useful? Is it sensible? What follows are the comments we received.

\section{Nora Lustig}

Editor, Forum Section 